\title{
Hepatobiliary transport in health and disease
}

\author{
Jeannie Chan ${ }^{\star}$ and John L VandeBerg \\ Southwest National Primate Research Center \& Department of Genetics, Texas Biomedical \\ Research Institute, PO Box 760549, San Antonio, TX, USA
}

\begin{abstract}
Bile salts, cholesterol and phosphatidylcholine are secreted across the canalicular membrane of hepatocytes into bile by ATP-binding cassette $(\mathrm{ABC})$ transporters. Secretion of bile salts by $\mathrm{ABCB} 11$ is essential for bile flow and for absorption of lipids and fat-soluble vitamins. ABCG5 and ABCG8 eliminate excess cholesterol and sterols from the body by secreting them into bile. There are two mechanisms to protect the canalicular membrane from solubilization by bile salts; ABCB4 secretes phosphatidylcholine into bile to form mixed micelles with bile salts, and ATP8B1 maintains the canalicular membrane in a liquid-ordered state. Three different forms of progressive familial intrahepatic cholestasis (PFIC) disorders, PFIC1, PFIC2 and PFIC3, are caused by mutations in $A T P 8 B 1, A B C B 11$ and $A B C B 4$, respectively. Sitosterolemia is caused by mutations in $A B C G 5$ and $A B C G 8$. This article reviews the physiological roles of these canalicular transporters, and the pathophysiological processes and clinical features associated with their mutations.
\end{abstract}

\section{Keywords}

ATP-binding cassette transporter; bile; canalicular membrane; cholestasis; cholesterol; P4 ATPase; phospholipids

\section{Secretion of bile by the liver}

The liver produces bile, which is essential for the elimination of endogenous compounds and xenobiotics from the body, for the emulsification of fat and for the intestinal absorption of lipids and fat-soluble vitamins. Bile is secreted into the canaliculi, which are small channels formed by the apical membranes of adjacent hepatocytes. Active secretion of organic solutes into the bile canaliculi by hepatocytes creates an osmotic gradient that causes water and electrolytes to flow from hepatocytes into the bile canaliculi. From the canaliculi, hepatic bile flows into the bile ducts, then through the bile ducts into the gallbladder. During fasting, bile is stored in the gallbladder, where water and electrolytes are absorbed and the organic solutes become more concentrated in gallbladder bile. During feeding, in response to stimulation by cholecystokinin and secretin, bile flows from the gallbladder into the small intestine [1,2].

Transporters located at the canalicular membrane efflux endogenous compounds (bile salts, phospholipids, cholesterol and bilirubin) and xenobiotics (drugs, carcinogens and their

\footnotetext{
(C) 2012 Future Medicine Ltd

*Author for correspondence: Tel.: +1 210258 9745, Fax: +1 210258 9883, jchan@txbiomedgenetics.org.

Financial \& competing interests disclosure

The authors have no other relevant affiliations or financial involvement with any organization or entity with a financial interest in or financial conflict with the subject matter or materials discussed in the manuscript apart from those disclosed.

No writing assistance was utilized in the production of this manuscript.
} 
metabolites) from the liver into bile. Many canalicular transporters are members of the ATPbinding cassette $(\mathrm{ABC})$ family. Bile salts are transported by $\mathrm{ABCB} 11$, and phospholipids are transported by ABCB4. ABCG5 and ABCG8 efflux cholesterol and plant sterols while $\mathrm{ABCC} 2$ transports bilirubin conjugates. $\mathrm{ABCB} 1, \mathrm{ABCC} 2, \mathrm{ABCG} 2$ and MATE1 function as efflux pumps to eliminate xenobiotics from the liver. CNT1 transports some drugs in addition to pyrimidines and adenosine. Lastly, ATP7B effluxes copper into bile [3].

The insertion of these transporters into the canalicular membrane is crucial for the transporters to function. A high concentration of bile salts in the bile canaliculi, along with their detergent nature, can damage the canalicular membrane and affect the formation of bile. A P-type ATPase protein, ATP8B1, maintains the canalicular membrane in a liquidordered state to withstand the attack by bile salts [4].

Defects in $A B C B 11, A B C B 4$ and $A T P 8 B 1$ cause progressive familial intrahepatic cholestasis (PFIC), a heterogeneous group of rare, autosomal recessive liver diseases of childhood. The estimated incidence is between 1:50,000 and 1:100,000 births [5]. Defects in either $A B C G 5$ or $A B C G 8$ cause an extremely rare autosomal recessive disease, sitosterolemia; only 80-100 cases have been reported worldwide [6]. Defects in $A B C C 2$ cause the autosomal recessive liver disorder called Dubin-Johnson syndrome. This is also a rare disease, with an incidence that ranges from 1:1300 among Iranian Jews [7] to 1:300,000 in a Japanese population [8]. This review focuses on the physiological roles of six canalicular transporters (ABCB11, ABCB4, ATP8B1, ABCG5, ACG8 and ABCC2; Figure 1 ) as well as the pathophysiological processes and clinical features associated with their mutations.

\section{Synthesis of bile salts}

The major organic constituents of bile are bile salts (the ionized form of bile acids). Bile salts are exclusively synthesized from cholesterol in the liver via two biosynthetic pathways. The classic pathway begins with 7-hydroxylation of cholesterol by the rate-limiting enzyme cholesterol 7a-hydroxylase. The alternative pathway begins with 27-hydroxylation of cholesterol by sterol 27-hydroxylase. Further modifications of the ring structure and side chain of cholesterol lead to the production of two primary bile acids that differ in 12hydroxylation. Cholic acid is 12-hydroxylated whereas chenodeoxycholic acid is not. An amino acid, glycine or taurine, is added to the sterol intermediates in the last step of biosynthesis. Conjugation of bile acids increases their amphipathicity, and the conjugated bile salts exist as anions at biliary and intestinal $\mathrm{pH}$ [9]. In humans, the majority of bile salts are conjugated with glycine [10].

The metabolism of cholesterol to bile salts transforms the hydrophobic cholesterol into amphipathic bile salts that have detergent properties. The biochemical nature of bile salts enables them to form micelles and solubilize lipids. Mixed micelles of phospholipids and bile salts in the canaliculi solubilize cholesterol effluxed by ABCG5 and ABCG8 to eliminate excess cholesterol from the body to maintain cholesterol homeostasis. Bile salts also solubilize long-chain fatty acids, fat-soluble vitamins, cholesterol and lipophilic drugs in the intestine to facilitate the absorption of these dietary lipids and drugs [11].

\section{Enterohepatic circulation of bile salts}

The human liver has a bile salt pool of 2-3 g, and synthesizes 500-600 $\mathrm{mg}$ of bile salts and secretes $20-30 \mathrm{~g}$ of bile salts daily. Therefore, most of the bile salts secreted at the canalicular (apical) membrane of hepatocytes are recycled by the enterohepatic circulation. The cycle begins with bile salts flowing from the liver into the lumen of the small intestine. In the distal ileum, bile salts (>90\%) are efficiently absorbed from the lumen by the ileal bile 
acid transporters. The reabsorbed bile salts are transported via portal blood back to the liver, taken up from blood at the sinusoidal (basolateral) membrane of hepatocytes and resecreted into bile to complete one cycle. Bile salts cycle six- to ten-times per day. A small amount of bile salts is lost in each cycle, which is replaced by bile salt synthesis $[2,12,13]$.

\section{Canalicular transport of bile salts}

Secretion of bile salts at the canalicular membrane drives the vectorial flow of bile salts from portal blood into bile. Moving bile salts from the hepatocyte against a higher concentration gradient into bile requires an ATP-dependent process; the concentration of bile salts in the canalicular lumen is 100- to 1000-fold higher than that in the cytoplasm of hepatocytes [2]. This process is mediated by ABCB11 (also known as BSEP or SPGP).

The substrates for $\mathrm{ABCB} 11$ are monovalent glycine- and taurine-conjugated bile salts. The rank order of ABCB11 preference for different conjugated bile salts is taurochenodeoxycholate $>$ taurocholate $>$ tauroursodeoxycholate $>$ glycocholate $[14,15]$. The sulfated bile salt, taurolithocholate 3-sulfate, is transported by human ABCB11 [15]. While bile salts are the main substrates that $\mathrm{ABCB} 11$ transports, other compounds (e.g., pravastatin) have been reported to be transported by ABCB11 [16].

The human $A B C B 11$ gene, located on chromosome 2q24, was identified by positional cloning in patients with PFIC type 2 (PFIC2) [17]. The fact that mutations in the $A B C B 11$ gene in PFIC2 patients lead to extremely low biliary bile salt concentrations $(<1 \%$ of normal) indicates that $\mathrm{ABCB} 11$ is the only protein in the liver that has bile salt transport function [18]. The protein encoded by $A B C B 11$ comprises 1321 amino acids. The predicted topology consists of two transmembrane domains with six transmembrane a-helix segments in each domain, and two cytoplasmic nucleotide-binding domains that contain the highly conserved ABCs [17].

$\mathrm{ABCB} 11$ expression is regulated at the transcriptional and post-transcriptional levels. The farnesoid X receptor (FXR) is the bile salt sensor in hepatocytes, with chenodeoxycholate being a strong ligand for FXR $[19,20]$. When activated by bile salts, FXR forms a heterodimer with the retinoid X receptor (RXR). The FXR-RXR complex enhances transcription from the $A B C B 11$ promoter $[21,22]$. This regulatory mechanism enables $\mathrm{ABCB} 11$ to respond to changes in the flow of bile salts through the hepatocytes as it is the key player in driving bile flow across the hepatocytes. When bile salt levels become elevated in hepatocytes, upregulating $\mathrm{ABCB} 11$ expression increases the efflux of bile salts from hepatocytes to normalize cellular levels of bile salts.

At the post-transcriptional level, glycosylation and phosphorylation regulate the localization of ABCB11 to the canalicular membrane. Furthermore, an intracellular pool of ABCB11 transporters can be mobilized to the canalicular membrane to provide a transient increase in $\mathrm{ABCB} 11$ expression; for instance, a fast response to a postprandial increase in bile salts [23].

\section{$A B C B 11$ \& liver disease}

Mutations in the $A B C B 11$ gene cause a spectrum of liver diseases that vary in severity. $\mathrm{ABCB} 11$ deficiency leads to cholestasis, a liver disease characterized by reduced bile secretion and decreased bile flow. The most severe form is PFIC2 (Table 1), a rare, autosomal recessive liver disease. The disease manifests in infants and progresses rapidly to cirrhosis with a need for liver transplantation within the first decade of life due to liver damage from the accumulation of bile salts. Clinical features are jaundice, intractable pruritus and vitamin deficiency. Patients have very low biliary bile salts but high serum bile 
salts. They have elevated serum alanine aminotransferase (ALT) activity but low or normal serum $\gamma$-glutamyltransferase ( $\gamma \mathrm{GT}$ ) activity. Serum cholesterol is occasionally elevated. Histological characteristics of the liver are giant cell hepatitis, bile duct proliferation and portal fibrosis. The appearance of bile as seen by electron microscopy is amorphous or filamentous. During the course of the disease, patients are likely to develop gallstones, and are at risk of developing hepatocellular carcinoma or cholangiocarcinoma [24,25].

More than 100 mutations have been identified in the $A B C B 11$ genes of PFIC2 patients: nonsense mutations, missense mutations, small insertions and deletions, splice site mutations and whole-gene deletions. The most common mutations are E297G and D482G [26]. The disease progresses more slowly in patients with $\mathrm{D} 482 \mathrm{G}$ mutations, and they develop cirrhosis at an older age [24]. Investigation of ABCB11 expression by immunochemistry revealed that the vast majority of biopsy specimens had little or no detectable staining, meaning that $\mathrm{ABCB} 11$ expression is frequently absent in PFIC2 patients [26].

A less severe form of cholestatic liver disease is benign recurrent intrahepatic cholestasis (BRIC). Some BRIC type 2 (BRIC2) patients have mutations in the $A B C B 11$ gene [27]. Drug-induced cholestasis occurs when ABCB11 function is inhibited by endogenous metabolites or drugs, which leads to intrahepatic cholestasis. Drugs such as cyclosporin A, rifampicin and glibenclamide inhibit bile salt transport by ABCB11. The V444A polymorphism is associated with susceptibility to drug-induced cholestasis and has been shown to be associated with lower ABCB11 expression levels. Intrahepatic cholestasis of pregnancy (ICP) affects women in the second or third trimester of pregnancy who otherwise have a normal medical history, and the liver disease resolves after delivery. Nonpregnant women who have suffered previously from ICP are susceptible to cholestasis induced by oral contraceptives. The V444A variant is also associated with ICP type 2 patients [28].

\section{Sources of hepatic phosphatidylcholine}

The second most abundant organic solutes in bile are phospholipids, mainly phosphatidylcholine (PC). PC is synthesized in the liver via two pathways. The Kennedy pathway, active in all tissues, converts choline into PC in three enzymatic steps and accounts for $70 \%$ of PC synthesis [29]. The remaining PC is synthesized by the phosphatidylethanolamine $N$-methyltransferase pathway. Phosphatidylethanolamine $N$ methyltransferase, expressed only in hepatocytes, catalyzes three reactions that sequentially methylate phosphatidylethanolamine (PE) to convert it to PC [30].

The liver also acquires PC from circulating HDL and LDL that it takes up [31,32]. A study by Portal et al. showed that $38 \%$ of PC secreted into bile was from PC on HDL delivered to the liver [31].

\section{Canalicular transport of PC}

The presence of $\mathrm{PC}$ in bile prevents damage to membranes of cells in the biliary tree by high concentrations of bile salts because mixed micelles of PC and bile salts reduce the detergent activity of monomeric bile salts and simple bile salt micelles to solubilize the lipids in the cell membrane. Furthermore, mixed micelles solubilize cholesterol better than simple bile salt micelles and prevent formation of gallstones. Translocation of PC from the inner to the outer leaflet of the canalicular membrane is mediated by the ABCB4 transporter, also known as MDR3 P-glycoprotein in humans, or Abcb4 and Mdr2 P-glycoprotein in mice. Once in the outer leaflet, $\mathrm{PC}$ is exposed and accessible for extraction by bile salts [33].

After the mouse $A b c b 4$ gene was cloned [34], its function remained unknown for several years, until $A b c b 4^{-1-}$ mice were generated. Mice that are homozygous for a disrupted $A b c b 4$ 
gene are unable to secrete PC into the bile, and the level of PC in bile of heterozygous mice is half that of wild-type mice [35]. However, PC secretion is restored by expressing the human $A B C B 4$ gene in $A b c b 4^{-1-}$ mice, demonstrating that the human $A B C B 4$ and mouse $A b c b 4$ genes play an essential role in PC secretion [36]. Studies with transfected cells expressing $\mathrm{ABCB} 4$ showed that $\mathrm{PC}$ is secreted into medium containing taurocholate, lending further support for the role of ABCB4 in the canalicular transport of PC [37-39].

The human $A B C B 4$ gene consists of 28 exons and spans $74 \mathrm{~kb}$ on chromosome $7 \mathrm{q} 21$ [40]. The ABCB4 protein is expressed only in the liver, although $A B C B 4$ transcripts are expressed at low levels in nonhepatic tissues such as the adrenal gland, heart, muscle, spleen and tonsil [41]. In the liver, $A B C B 4 \mathrm{mRNA}$ expression is regulated by bile salts and FXR [42]. Bile salts and the synthetic FXR agonist GW4064 enhance $A B C B 4$ transcription by activating the FXR-RXR heterodimers to bind to an FXR response element in the distal promoter of the $A B C B 4$ gene [42]. The fact that $A B C B 4$ and $A B C B 11$ are both FXR target genes suggests that secretion of $\mathrm{PC}$ and bile salts is regulated coordinately, such that the canalicular membrane of hepatocytes is protected against an increase in bile salts by a concomitant increase in PC to ensure there is sufficient PC to form mixed micelles with bile salts.

\section{$A B C B 4$ \& liver disease}

Mutations in the $A B C B 4$ gene that result in loss of protein expression or loss of protein function lead to a severe recessive liver disease, PFIC type 3 (PFIC3) (Table 1). The first symptoms of jaundice, hepatomegaly, splenomegaly and pruritus may appear in patients as early as 1 month after birth or up to 20 years of age. In half of patients, the disease progresses to liver failure and liver transplantation is required at a mean age of 7.5 years $[25,43]$. Nonsense and frameshift mutations give rise to truncated proteins that are not detectable by immunostaining. Missense mutations in the conserved amino acids of the Walker A and B motifs and in the transmembrane domains disrupt the transport function of $\mathrm{ABCB} 4$. The absence of $\mathrm{ABCB} 4$ protein is found in patients with severe clinical phenotypes. In cases where the mutated $\mathrm{ABCB} 4$ has residual transporter activity, the onset of PFIC3 is later and progression of the disease is slower [33,43].

PFIC3 patients exhibit reduced concentrations of biliary PC (1-15\% of normal) but normal concentrations of biliary bile salts. Their serum bile salt concentrations are elevated, as are serum ALT and $\gamma \mathrm{GT}$ activities. High serum $\gamma \mathrm{GT}$ activity is an indicator that distinguishes PFIC3 patients from those with PFIC type 1 (PFIC1) and PFIC2 diseases. Liver histology reveals bile duct proliferation and portal fibrosis at the time of diagnosis, and biliary cirrhosis at an advanced stage. These histologic findings are due to the impairment of biliary secretion of PC, which allows the detergent action of bile salts to attack the bile canaliculi and biliary epithelium (Figure 2B). The observation of hepatocellular cholestasis and bile plugs in the ductules is due to crystallization of cholesterol because monomeric bile salts have a lower solubility for cholesterol $[25,43]$.

Heterozygous $A B C B 4$ mutations or homozygous missense mutations that reduce but do not eliminate ABCB4 activity predispose to several cholestatic diseases. Low phospholipidassociated cholestasis is related to a high biliary cholesterol saturation index that favors formation of gallstones. Multiple genetic defects underlie the development of abnormal canalicular transport in ICP and one of them is a defect in $A B C B 11$, as mentioned previously. In patients with ICP and elevated serum $\gamma \mathrm{GT}$ activity, the most likely genetic predisposition is a heterozygous $A B C B 4$ defect. Perinatal distress may cause children with a genetic predisposition to develop transient neonatal cholestasis. The clinical symptoms resolve when treated with ursodeoxycholic acid (UDCA) [33,43]. 


\section{Distribution of phospholipids in canalicular membranes}

Membranes composed of PC, PE and phosphatidylserine (PS) are loosely packed because of the unsaturated fatty acyl chains in these phospholipids, and they are in the liquid-disordered state. The lipids in these membranes are sensitive to solubilization by detergents. By contrast, membranes composed of sphingolipids and cholesterol are more rigid because the saturated fatty acyl chains of sphingolipids combine with cholesterol to pack the lipids more tightly. These membranes are in the liquid-ordered state, and they are resistant to detergents. Phospholipids in the inner and outer leaflets of the canalicular membrane of hepatocytes are distributed in an asymmetric fashion so that the membrane can withstand high concentrations of bile salts in the bile canaliculi. PC, sphingolipids and cholesterol are localized in the outer leaflet of the membrane, whereas PE and PS are localized in the inner leaflet $[44,45]$.

There is a tendency for phospholipids to equilibrate between the two leaflets of the bilayers, so proteins termed floppase and flippase are needed to maintain their asymmetric distribution in the membrane. Translocation of phospholipids between the two leaflets of the membrane is an ATP-dependent process. ABCB4 is a floppase that translocates PC from the inner to the outer leaflet, whereas ATP8B1 is a flippase that translocates PS from the outer to the inner leaflet (Figure 2). The flopping of PC by ABCB4 is essential for secretion of PC into bile (see above). The flipping of PS by ATP8B1 keeps the membrane in the liquidordered state for secretion of bile salts into bile (see below).

\section{Synthesis of PS}

Mammalian cells contain two PS synthases that produce PS using different substrates. PS is synthesized by replacing the head group of PC with serine by PS synthase (PSS) 1 or the same serine exchange reaction using PE by PSS2 [46]. Studies in mice revealed redundancy in these two enzymes. While mice lacking both PSS1 and PSS2 are not viable, mice lacking either PSS1 or PSS2 appear normal. As little as $10 \%$ of normal serine exchange activity is needed for survival $[47,48]$.

\section{ATP8B1 mediates inward translocation of PS}

ATP8B1, also known as FIC1, is a transmembrane protein that belongs to the type 4 subfamily of P-type ATPases. The signature sequence of P-type ATPase contains an aspartic acid residue that is phosphorylated during the transport cycle, and the name 'P-type' refers to the phosphorylated intermediate. The ATP8B1 gene contains 28 exons and spans at least $77 \mathrm{~kb}$ on chromosome 18q21 [49]. The ATP8B1 protein has ten transmembrane segments and a large intracellular loop containing the P-type signature sequence and an ATP-binding site [50].

ATP8B1 is expressed not only in the liver, but also in other tissues, such as the pancreas, small intestine, bladder, heart, stomach, prostate and lung [51]. Maturation, transport and functioning of ATP8B1 require the chaperone protein CDC50A. In the absence of heterodimerization with CDC50A, ATP8B1 is retained in the endoplasmic reticulum and degraded prematurely. In the presence of CDC50A, ATP8B1 exits from the endoplasmic reticulum and translocates to the plasma membranes where it functions as a flippase in concert with the CDC50A subunit $[52,53]$.

Several studies present evidence for flippase activity of ATP8B1 in the canalicular membrane. Paulusma et al. reported a significant increase of PS in the bile of Atp8b1deficient mice when hydrophobic bile salts were infused into these mice but not in wild-type mice [54]. In another study, Paulusma et al. reported an enhanced internalization of 
fluorescent-labeled PS analogs in mammalian cells genetically engineered to express ATP8B1 and CDC50 proteins [52]. Using siRNA to reduce ATP8B1 expression in rat hepatocyte sandwich cultures, Cai et al. showed an accumulation of fluorescent-labeled PS analogs in the bile canaliculi in the presence of chenodeoxycholic acids [55]. Furthermore, they presented electron micrographs showing evidence of membrane damage by chenodeoxycholic acids in Atp8b1-knock-down rat hepatocytes. Taken together, these results demonstrate that ATP8B1 is involved in the translocation of PS to the inner leaflet of the membrane, and that the loss of flippase activity is associated with damage in the canalicular membrane when it is exposed to hydrophobic bile salts.

In the process of forming bile salt mixed micelles, extraction of PC and cholesterol from the outer leaflet of the canalicular membrane allows the spontaneously flopped PS to remain in the outer leaflet of the membrane. ATP8B1 flips PS back to the inner leaflet to ensure that the phospholipid asymmetry is not perturbed by the accumulation of PS in the outer leaflet.

\section{ATP8B1 \& liver disease}

PFIC1 is an autosomal recessive disorder caused by mutations in the $A T P 8 B 1$ gene on chromosome 18q21 [51]. It is also known as Byler disease [56] and Greenland familial cholestasis [57]. The causative mutation in PFIC1 patients in the Amish population who are descendants of Jacob Byler (whose name is associated with this disease) is a homozygous G-T mutation resulting in the substitution of glycine with valine at amino acid 308 [51,58]. PFIC1 patients in Inuit families in Greenland and Canada have a G-A mutation, resulting in the substitution of aspartate with asparagine at amino acid 554 [57]. The G308V missense mutation in Byler disease and the D554N missense mutation in Greenland familial cholestasis lead to an absence of canalicular expression of ATP8B1 [59]. Other ATP8B1 mutations that affect splicing or the protein structure have been identified in different populations [49].

PFIC1 patients develop cholestasis in early infancy and it progresses to end-stage liver disease before adulthood (Table 1). Serum bile salt and bilirubin concentrations are elevated, as is serum ALT activity, but serum $\gamma \mathrm{GT}$ activity is normal. Biliary bile salt concentrations are low. In addition to jaundice, severe pruritus and malabsorption of fats and fat-soluble vitamins, PFIC1 patients exhibit symptoms such as diarrhea, pancreatitis, hearing loss and pneumonia because of extrahepatic expression of ATP8B1. PFIC1 and PFIC2 share many clinical and pathologic features but only PFIC1 patients show extrahepatic symptoms $[24,25]$. Liver histology reveals canalicular cholestasis, with little hepatocellular necrosis and giant cell transformation. Electron microscopy reveals coarse and granular bile, and the appearance of bile from PFIC1 patients is different from the amorphous bile of PFIC2 patients as described by Bull et al. [60].

BRIC type 1 (BRIC1) is a less severe form of liver disease caused by ATP8B1 deficiency. While the expression or function of ATP8B1 is severely compromised by PFIC1 mutations, this occurs to a lesser extent with BRIC1 mutations [49,59]. The onset of BRIC1 is in childhood or adulthood, and recurrent episodes of cholestasis resolve spontaneously without permanent liver damage. In rare cases of ICP, heterozygous mutations in ATP8B1 have been reported [61,62].

Loss of normal phospholipid asymmetry of the canalicular membrane is key to understanding the pathophysiologic mechanism by which PFIC1 or BRIC1 mutations cause cholestasis (Figure 2C). When PS that flops spontaneously to the outer leaflet is not flipped back to the inner leaflet by ATP8B1, PS accumulates in the outer leaflet. The outer leaflet of the membrane is exposed to very high concentrations of bile salts in the bile canaliculi. As the outer leaflet of the canalicular membrane becomes liquid-disordered, it is less resistant to 
attack by bile salts as evidenced by elevated levels of PS and cholesterol in bile [54]. Changes in the lipid composition of the membrane, especially a reduction in cholesterol content, impair bile salt secretion by ABCB11 and lead to the development of cholestasis [63].

\section{Treatment of PFIC/BRIC disorders}

PFIC/BRIC disorders are treated with UDCA, rifampicin and surgical interventions. UDCA therapy aims to reduce the cytotoxic effects of bile acids on the canalicular membrane by replacing the endogenous bile acids (cholic acid and chenodeoxycholic acid) with a less hydrophobic bile acid, UDCA. UDCA is the therapy of choice for PFIC3 patients with residual ABCB4 function. Rifampicin induces expression of the CYP450 enzyme CYP3A4, thereby increasing $6 a$-hydroxylation of bile acids. The hydroxylated bile acids are subsequently excreted in urine as $6 a$-hydroxylated bile acid glucuronides. Rifampicin therapy reduces pruritus in some PFIC1 patients and aborts cholestatic episodes in BRIC1 and BRIC2 patients. Patients are monitored for side effects of rifampicin affecting liver functions. Surgical intervention is the treatment of choice for PFIC1 and PFIC2 patients, and should be performed as soon as possible after diagnosis to prevent liver damage. The procedure, partial external biliary diversion, aims to decrease the bile salt pool by reducing reabsorption of bile salts. The enterohepatic circulation of bile salts is interrupted by a jejunal conduit from the gallbladder to the abdominal wall. An endoscopic biliary diversion, nasobiliary drainage, is effective in aborting a cholestatic episode in BRIC patients.

When all of these treatments fail, the only option is liver transplantation. While the canalicular defects are cured by a liver transplant, lifelong medication with immunosuppressive drugs is needed to control tissue rejection. For PFIC1 patients, the extrahepatic symptoms persist, and some even worsen (e.g., diarrhea) after the liver transplant. In some cases, the transplanted liver develops steatohepatitis [64].

\section{Sources of biliary cholesterol \& plant sterols}

Secretion of free cholesterol into bile eliminates excess cholesterol from the body. About $1 \mathrm{~g}$ of cholesterol is secreted daily into bile, and half of it is disposed of as neutral sterol in feces [65]. The two sources of hepatic cholesterol secreted into the bile are from de novo synthesis, and from lipoproteins that are taken up by the liver [66]. Cholesterol derived from HDL is preferentially utilized for biliary secretion $[67,68]$.

The circulating levels of noncholesterol sterols (plant and shellfish sterols) are very low compared with cholesterol; $<1 \mathrm{mg} / \mathrm{dl}$ plant sterol versus $200 \mathrm{mg} / \mathrm{dl}$ cholesterol [69]. Humans cannot synthesize plant sterols and absorb them poorly (5\% plant sterols vs $~ 50 \%$ dietary cholesterol) [70,71]; therefore, only a small amount of plant sterols is found in the blood. Circulating plant sterols taken up by the liver are secreted into bile for fecal excretion.

\section{Canalicular transport of cholesterol}

Cholesterol and sterols are secreted into bile by the ABCG5 and ABCG8 proteins. Identification of the genes in the STSL locus on chromosome 2p21 [72] that underlie the genetic defect of sitosterolemia led to the discovery of two genes that encode the ABCG5 and ABCG8 proteins [73-75]. Each of the two highly homologous genes has 13 exons, and together they span $80 \mathrm{~kb}$. The genes are arranged in a head-to-head configuration, separated by 140 bases between their first exons, and are transcribed in opposite directions [74,75]. The encoded proteins are half-transporters, each containing six transmembrane a-helix segments and one ATP-binding site at the amino terminus. ABCG5 and ABCG8 dimerize and function as an obligate heterodimer [73,76]. 
Expression of ABCG5 and ABCG8 is restricted to the canalicular membrane of hepatocytes and the apical membrane of enterocytes [77]. In the liver, ABCG5 and ABCG8 transport cholesterol and plant sterols from hepatocytes into bile for disposal from the body in feces [6]. Exactly how ABCG5 and ABCG8 transport sterols is not fully understood. A study by Kosters et al. suggested that ABCG5 and ABCG8 flop sterols from the inner to the outer leaflet of the plasma membrane [78], and Small suggested that the sterols are subsequently lifted out of the membrane bilayer by ABCG5 and ABCG8 so that they can be extracted by bile salt micelles [79].

\section{Pathophysiology of sitosterolemia}

The disorder sitosterolemia got its name from sitosterol, the major plant sterol [80]. The genetic defect in sitosterolemia is caused by homologous mutations in either the $A B C G 5$ or $A B C G 8$ genes, which impair the function of the ABCG5-ABCG8 heterodimers [73-75]. Mutations in $A B C G 8$ are more prevalent in Caucasians, whereas mutations in $A B C G 5$ are more prevalent in the Japanese, reflecting mutations in different founder populations [75].

Apart from their role in biliary cholesterol and sterol excretion, ABCG5 and ABCG8 are involved in regulating absorption of cholesterol and sterols in the intestine. Plant sterols are preferentially transported out of the enterocytes back to the lumen by ABCG5 and ABCG8 to limit the absorption of plant sterols to less than 5\%. By comparison, a smaller fraction of cholesterol is effluxed to the lumen, and approximately $50 \%$ of dietary cholesterol is absorbed [70,71].

Impaired intestinal function of ABCG5 and ABCG8 increases absorption of cholesterol and sterols, and impaired liver function of ABCG5 and ABCG8 decreases biliary excretion of cholesterol and sterols, leading to slightly or moderately elevated blood levels of cholesterol but highly elevated blood levels (30- to 100-fold) of plant sterols [69,75,81]. As plant sterols accumulate in blood and tissues, patients develop tendon xanthomas and premature coronary atherosclerosis. Other clinical symptoms are hemolysis, arthralgias, thrombocytopenia and hypersplenism [6].

\section{Treatment of sitosterolemia}

Plasma levels of plant sterols in a sitosterolemic patient with chronic hepatitis and cirrhosis were almost normalized after he received a liver transplant [82]. Despite the genetic defect in the intestine, the observation that restoration of ABCG5-ABCG8 activity in the liver is able to keep plant sterols at low levels in the blood suggests that biliary elimination of plant sterols plays a greater role in controlling plasma plant sterols than has been previously recognized [82].

Conventional treatments for sitosterolemia include a low-plant-sterol diet, bile salt-binding resins and partial ileal bypass surgery [83]. Conventional drug treatment in combination with ezetimibe has been shown to be more efficacious than treatment without ezetimibe in reducing plasma plant sterols in sitosterolemia patients, particularly in those who are not responsive to conventional drugs [83-85]. Ezetimibe is a drug that inhibits intestinal cholesterol and sterol absorption by the NPC1L1 protein [86-88]. NPC1L1 is a transmembrane protein expressed in the canalicular membrane of hepatocytes and in the apical membrane of enterocytes. In humans, expression of NPC1L1 mRNA in the liver is higher than that in the small intestine [89]. NPC1L1 transports cholesterol and plant sterols, but in the opposite direction to the transport of cholesterol and sterols by ABCG5 and ABCG8. It mediates the uptake of cholesterol and sterols from the lumen into enterocytes and the uptake of cholesterol and sterols from the bile into hepatocytes. Ezetimibe reduces 
plasma sterol concentrations by blocking absorption of sterols in the intestine and by inhibiting NPC1L1 activity in the liver to promote biliary sterol excretion [90].

\section{Canalicular transport of organic anions}

The ABCC2 protein (also known as MRP2) transports many organic anions that are conjugated with glutathione, glucuronate or sulfate from hepatocytes into bile for elimination from the body. It also plays an important role in the excretion of bilirubin conjugates [91].

The $A B C C 2$ gene is located on chromosome 10q24 [92]. Its 32 exons encode a protein of 1545 amino acids $[93,94]$. The predicted topology of ABCC 2 contains three transmembrane domains with 17 transmembrane segments and two nucleotide-binding sites. Localization of $\mathrm{ABCC} 2$ in the apical membrane is determined by the transmembrane domain at the $\mathrm{N}$ terminus and a region in the $\mathrm{C}$-terminus [95].

Besides being expressed in the canalicular membrane of hepatocytes, $\mathrm{ABCC} 2$ is also expressed in the apical membrane of other cell types, such as kidney and intestinal cells [96,97]. In addition, ABCC 2 can be detected in some malignant tumors, where it confers resistance to anticancer drugs by transporting them out of the tumor cells $[98,99]$.

\section{$A B C C 2$ \& liver disease}

The hereditary form of ABCC2 deficiency is known as Dubin-Johnson syndrome. It is characterized by an elevated concentration of bilirubin glucuronides in blood, and by a dark pigment deposited in hepatocytes, which gives the liver a dark-blue or black appearance $[100,101]$. The impairment of biliary secretion of bilirubin glucuronides upregulates the ABCC 3 transporter in the basolateral membrane of hepatocytes [102]. The ABCC3 protein transports bilirubin glucuronides from hepatocytes into blood, leading to an increase in serum levels of bilirubin glucuronides in patients with Dubin-Johnson syndrome.

The disease usually manifests during adolescence. Major clinical symptoms are recurrent or persistent jaundice without pruritus and abdominal pain. Dubin-Johnson syndrome is a benign disorder. No treatment is necessary and patients have a normal life expectancy [103]. The $A B C C 2$ mutations identified in Dubin-Johnson patients include splice-site mutations, nonsense mutations, missense mutations and small deletions, which cause an absence of $\mathrm{ABCC} 2$ expression or expression of a functionally inactive protein [104].

\section{Conclusion}

The identification and characterization of the transporters in the canalicular membranes of hepatocytes have advanced our understanding of the molecular process of bile formation. The interplay among these transporters enables the secretion of organic solutes into bile and protects the membranes of cells in the biliary tree from damage by bile salts so that bile formation is not disrupted. The severe liver disorders PFIC types 1, 2 and 3 underscore the crucial roles of ATP8B1, ABCB11 and ABCB4 in bile formation.

\section{Future perspective}

A therapeutic strategy for PFIC disorders is to ameliorate the absence or decreased expression of mutated proteins that have transporter activity in the canalicular membrane. One class of drugs suppresses premature termination of protein translation at stop codons due to nonsense mutations. PTC124 (ataluren) is the first available drug of this class and its efficacy in PFIC patients with nonsense mutations has yet to be determined in clinical trials 
[105]. Another class of drugs acts as a pharmacological chaperone to stabilize proteins misfolded due to missense mutations so that they are not trapped in the endoplasmic reticulum and subsequently degraded in proteasomes. The pharmacological chaperone 4phenylbutyrate acid was shown to be effective in increasing cell surface expression of mutated ATP8B1 [106] and ABCB11 [107] proteins in vitro, but the drug has not been tested in PFIC1 and 2 patients. Development of drugs with these mechanisms of action may reduce the deficiency in hepatobiliary transport of PFIC patients.

Recent developments in genome editing technology hold promise for correcting gene mutations of PFIC patients. Zinc finger nuclease [108] and transcription activator-like effector nuclease [109] can be engineered to recognize a specific gene sequence and induce a double-strand break at the targeted site. The double-strand break is then repaired with an exogenous fragment of DNA without mutations by homologous recombination, which is an intrinsic DNA repair mechanism of the cell [110]. Studies have shown that the efficiency of homologous recombination is increased by zinc finger nuclease-mediated genome editing [108]. Progress in genome editing technology may make it possible to use gene therapy to treat PFIC disorders in the future.

\section{Acknowledgments}

This work was supported by NIH grant R01 DK065058, and by a grant from the Robert J Kleberg Jr and Helen C Kleberg Foundation.

\section{References}

Papers of special note have been highlighted as:

- of interest

- of considerable interest

1. Hofmann, AF. Overview of bile secretion. In: Schultz, SG., editor. Handbook of Physiology. MD, USA: American Physiological Society; 1989. p. 549-566.

2. Trauner M, Boyer JL. Bile salt transporters: molecular characterization, function, and regulation. Physiol. Rev. 2003; 83(2):633-671. [PubMed: 12663868]

3. Klaassen CD, Aleksunes LM. Xenobiotic, bile acid, and cholesterol transporters: function and regulation. Pharmacol. Rev. 2010; 62(1):1-96. [PubMed: 20103563]

4. Folmer DE, Elferink RP, Paulusma CC. P4 ATPases - lipid flippases and their role in disease. Biochim. Biophys. Acta. 2009; 1791(7):628-635. [PubMed: 19254779]

5. Davit-Spraul A, Gonzales E, Baussan C, Jacquemin E. Progressive familial intrahepatic cholestasis. Orphanet. J. Rare Dis. 2009; 4:1. [PubMed: 19133130]

6. Kidambi S, Patel SB. Sitosterolaemia: pathophysiology, clinical presentation and laboratory diagnosis. J. Clin. Pathol. 2008; 61(5):588-594. [PubMed: 18441155]

7. Shani M, Seligsohn U, Gilon E, Sheba C, Adam A. Dubin-Johnson syndrome in Israel. I. Clinical, laboratory, and genetic aspects of 101 cases. Q. J. Med. 1970; 39(156):549-567. [PubMed: 5532959]

8. Kajihara S, Hisatomi A, Mizuta T, et al. A splice mutation in the human canalicular multispecific organic anion transporter gene causes Dubin-Johnson syndrome. Biochem. Biophys. Res. Commun. 1998; 253(2):454-457. [PubMed: 9878557]

9. Russell DW. The enzymes, regulation, and genetics of bile acid synthesis. Annu. Rev. Biochem. 2003; 72:137-174. [PubMed: 12543708]

10. Marschall, HU.; Matern, H.; Sjövall, J.; Matern, S. Conjugation of bile acids. In: Fromm, H.; Leuschner, U., editors. Bile Acids - Cholestasis - Gallstones: Advances in Basic and Clinical Bile Acid Research. The Netherlands: Kluwer, Dordrecht; 1996. p. 13-22. 
11. Hofmann AF. Bile acids: trying to understand their chemistry and biology with the hope of helping patients. Hepatology. 2009; 49(5):1403-1418. [PubMed: 19296471]

12. Suchy FJ, Sippel CJ, Ananthanarayanan M. Bile acid transport across the hepatocyte canalicular membrane. FASEB J. 1997; 11(4):199-205. [PubMed: 9068608]

13. Dawson PA, Lan T, Rao A. Bile acid transporters. J. Lipid Res. 2009; 50(12):2340-2357. [PubMed: 19498215]

14. Noe J, Stieger B, Meier PJ. Functional expression of the canalicular bile salt export pump of human liver. Gastroenterology. 2002; 123(5):1659-1666. [PubMed: 12404240]

15. Hayashi H, Takada T, Suzuki H, Onuki R, Hofmann AF, Sugiyama Y. Transport by vesicles of glycine- and taurine-conjugated bile salts and taurolithocholate 3-sulfate: a comparison of human BSEP with rat Bsep. Biochim. Biophys. Acta. 2005; 1738(1-3):54-62. [PubMed: 16332456]

16. Hirano M, Maeda K, Hayashi H, Kusuhara H, Sugiyama Y. Bile salt export pump (BSEP/ ABCB11) can transport a nonbile acid substrate, pravastatin. J. Pharmacol. Exp. Ther. 2005; 314(2):876-882. [PubMed: 15901796]

17. Strautnieks SS, Bull LN, Knisely AS, et al. A gene encoding a liver-specific ABC transporter is mutated in progressive familial intrahepatic cholestasis. Nat. Genet. 1998; 20(3):233-238.

[PubMed: 9806540] - Reports cloning of the $A B C B 11$ gene from progressive familial intrahepatic cholestasis (PFIC) type 2 patients.

18. Jansen PL, Strautnieks SS, Jacquemin E, et al. Hepatocanalicular bile salt export pump deficiency in patients with progressive familial intrahepatic cholestasis. Gastroenterology. 1999; 117(6): 1370-1379. [PubMed: 10579978]

19. Parks DJ, Blanchard SG, Bledsoe RK, et al. Bile acids: natural ligands for an orphan nuclear receptor. Science. 1999; 284(5418):1365-1368. [PubMed: 10334993]

20. Lew JL, Zhao A, Yu J, et al. The farnesoid X receptor controls gene expression in a ligand-and promoter-selective fashion. J. Biol. Chem. 2004; 279(10):8856-8861. [PubMed: 14684751]

21. Ananthanarayanan M, Balasubramanian N, Makishima M, Mangelsdorf DJ, Suchy FJ. Human bile salt export pump promoter is transactivated by the farnesoid $\mathrm{X}$ receptor/bile acid receptor. J. Biol. Chem. 2001; 276(31):28857-28865. [PubMed: 11387316]

22. Sinal CJ, Tohkin M, Miyata M, Ward JM, Lambert G, Gonzalez FJ. Targeted disruption of the nuclear receptor FXR/BAR impairs bile acid and lipid homeostasis. Cell. 2000; 102(6):731-744. [PubMed: 11030617]

23. Lam P, Soroka CJ, Boyer JL. The bile salt export pump: clinical and experimental aspects of genetic and acquired cholestatic liver disease. Semin. Liver Dis. 2010; 30(2):125-133. [PubMed: 20422495]

24. Pawlikowska L, Strautnieks S, Jankowska I, et al. Differences in presentation and progression between severe FIC1 and BSEP deficiencies. J. Hepatol. 2010; 53(1):170-178. [PubMed: 20447715]

25. Morotti RA, Suchy FJ, Magid MS. Progressive familial intrahepatic cholestasis (PFIC) type, 1, 2, and 3: a review of the liver pathology findings. Semin. Liver Dis. 2011; 31(1):3-10. [PubMed: 21344347] - Excellent review of the histological features of the three PFIC disorders.

26. Strautnieks SS, Byrne JA, Pawlikowska L, et al. Severe bile salt export pump deficiency: 82 different $A B C B 11$ mutations in 109 families. Gastroenterology. 2008; 134(4):1203-1214. [PubMed: 18395098] * A study of $A B C B 11$ mutations in 109 PFIC type 2 families and ABCB11 protein expression in a large number of liver samples from patients.

27. van Mil SW, van der Woerd WL, van der Brugge G, et al. Benign recurrent intrahepatic cholestasis type 2 is caused by mutations in $A B C B 11$. Gastroenterology. 2004; 127(2):379-384. [PubMed: 15300568]

28. Stieger B. Role of the bile salt export pump, BSEP, in acquired forms of cholestasis. Drug Metab. Rev. 2010; 42(3):437-445. [PubMed: 20028269]

29. Kennedy EP, Weiss SB. The function of cytidine coenzymes in the biosynthesis of phospholipides. J. Biol. Chem. 1956; 222(1):193-214. [PubMed: 13366993]

30. Vance DE, Ridgway ND. The methylation of phosphatidylethanolamine. Prog. Lipid Res. 1988; 27(1):61-79. [PubMed: 3057511] 
31. Portal I, Clerc T, Sbarra V, et al. Importance of high-density lipoprotein-phosphatidylcholine in secretion of phospholipid and cholesterol in bile. Am. J. Physiol. 1993; 264(6 Pt 1):G1052-G1056. [PubMed: 8333532]

32. Minahk C, Kim KW, Nelson R, Trigatti B, Lehner R, Vance DE. Conversion of low density lipoprotein-associated phosphatidylcholine to triacylglycerol by primary hepatocytes. J. Biol. Chem. 2008; 283(10):6449-6458. [PubMed: 18175806]

33. Oude Elferink RP, Paulusma CC. Function and pathophysiological importance of ABCB4 (MDR3 P-glycoprotein). Pflugers Arch. 2007; 453(5):601-610. [PubMed: 16622704]

34. Gros P, Raymond M, Bell J, Housman D. Cloning and characterization of a second member of the mouse Mdr gene family. Mol. Cell. Biol. 1988; 8(7):2770-2778. [PubMed: 3405218]

35. Smit JJ, Schinkel AH, Oude Elferink RP, et al. Homozygous disruption of the murine Mdr2 Pglycoprotein gene leads to a complete absence of phospholipid from bile and to liver disease. Cell. 1993; 75(3):451-462. [PubMed: 8106172] - First report that mice lacking Mdr2 P-glycoprotein do not secrete phosphatidylcholine into bile.

36. Smith AJ, de Vree JM, Ottenhoff R, Oude Elferink RP, Schinkel AH, Borst P. Hepatocyte-specific expression of the human MDR3P-glycoprotein gene restores the biliary phosphatidylcholine excretion absent in Mdr2 (-/-) mice. Hepatology. 1998; 28(2):530-536. [PubMed: 9696021]

37. Morita SY, Kobayashi A, Takanezawa Y, et al. Bile salt-dependent efflux of cellular phospholipids mediated by ATP binding cassette protein B4. Hepatology. 2007; 46(1):188-199. [PubMed: 17523162]

38. Ikebuchi Y, Takada T, Ito K, et al. Receptor for activated C-kinase 1 regulates the cellular localization and function of ABCB4. Hepatol. Res. 2009; 39(11):1091-1107. [PubMed: 19674157]

39. Groen A, Romero MR, Kunne C, et al. Complementary functions of the flippase ATP8B1 and the floppase ABCB4 in maintaining canalicular membrane integrity. Gastroenterology. 2011; 141(5): 1927-1937. e1-e4. [PubMed: 21820390] m Demonstrates the role of ATP8B1 in protecting the canalicular membrane from solubilization by bile salts.

40. Lincke CR, Smit JJ, van der Velde-Koerts T, Borst P. Structure of the human MDR3 gene and physical mapping of the human MDR locus. J. Biol. Chem. 1991; 266(8):5303-5310. [PubMed: 2002063]

41. Smit JJ, Schinkel AH, Mol CA, et al. Tissue distribution of the human MDR3 P-glycoprotein. Lab. Invest. 1994; 71(5):638-649. [PubMed: 7734012]

42. Huang L, Zhao A, Lew JL, et al. Farnesoid X receptor activates transcription of the phospholipid pump MDR3. J. Biol. Chem. 2003; 278(51):51085-51090. [PubMed: 14527955]

43. Gonzales E, Davit-Spraul A, Baussan C, Buffet C, Maurice M, Jacquemin E. Liver diseases related to $M D R 3$ ( $A B C B 4)$ gene deficiency. Front. Biosci. 2009; 14:4242-4256. [PubMed: 19273348]

44. Holthuis JC, Levine TP. Lipid traffic: floppy drives and a superhighway. Nat. Rev. Mol. Cell Biol. 2005; 6(3):209-220. [PubMed: 15738987]

45. Oude Elferink RP, Paulusma CC, Groen AK. Hepatocanalicular transport defects: pathophysiologic mechanisms of rare diseases. Gastroenterology. 2006; 130(3):908-925. [PubMed: 16530529]

46. Vance JE, Steenbergen R. Metabolism and functions of phosphatidylserine. Prog. Lipid Res. 2005; 44(4):207-234. [PubMed: 15979148]

47. Bergo MO, Gavino BJ, Steenbergen R, et al. Defining the importance of phosphatidylserine synthase 2 in mice. J. Biol. Chem. 2002; 277(49):47701-47708. [PubMed: 12361952]

48. Arikketh D, Nelson R, Vance JE. Defining the importance of phosphatidylserine synthase-1 (PSS1): unexpected viability of PSS1-deficient mice. J. Biol. Chem. 2008; 283(19):12888-12897. [PubMed: 18343815]

49. Klomp LW, Vargas JC, van Mil SW, et al. Characterization of mutations in ATP8B1 associated with hereditary cholestasis. Hepatology. 2004; 40(1):27-38. [PubMed: 15239083] $\boldsymbol{~}$ A study of $A T P 8 B 1$ mutations in 130 PFIC type 1 families and $A T P B 1$ mutations in 50 benign recurrent intrahepatic cholestasis type 1 families. 
50. Paulusma CC, Oude Elferink RP. The type 4 subfamily of P-type ATPases, putative aminophospholipid translocases with a role in human disease. Biochim. Biophys. Acta. 2005; 1741(1-2):11-24. [PubMed: 15919184]

51. Bull LN, van Eijk MJ, Pawlikowska L, et al. A gene encoding a P-type ATPase mutated in two forms of hereditary cholestasis. Nat. Genet. 1998; 18(3):219-224. [PubMed: 9500542] • Reports cloning of the $A T P 8 B 1$ gene from PFIC type 1 and benign recurrent intrahepatic cholestasis type 1 patients.

52. Paulusma CC, Folmer DE, Ho-Mok KS, et al. ATP8B1 requires an accessory protein for endoplasmic reticulum exit and plasma membrane lipid flippase activity. Hepatology. 2008; 47(1): 268-278. [PubMed: 17948906] - Demonstrates that CDC50 proteins are integral components of the flippase machinery.

53. Bryde S, Hennrich H, Verhulst PM, Devaux PF, Lenoir G, Holthuis JC. CDC50 proteins are critical components of the human class-1 P4-ATPase transport machinery. J. Biol. Chem. 2010; 285(52):40562-40572. [PubMed: 20961850]

54. Paulusma CC, Groen A, Kunne C, et al. Atp8b1 deficiency in mice reduces resistance of the canalicular membrane to hydrophobic bile salts and impairs bile salt transport. Hepatology. 2006; 44(1):195-204. [PubMed: 16799980]

55. Cai SY, Gautam S, Nguyen T, Soroka CJ, Rahner C, Boyer JL. ATP8B1 deficiency disrupts the bile canalicular membrane bilayer structure in hepatocytes, but FXR expression and activity are maintained. Gastroenterology. 2009; 136(3):1060-1069. [PubMed: 19027009]

56. Clayton RJ, Iber FL, Ruebner BH, McKusick VA. Byler disease. Fatal familial intrahepatic cholestasis in an Amish kindred. Am. J. Dis. Child. 1969; 117(1):112-124. [PubMed: 5762004]

57. Klomp LW, Bull LN, Knisely AS, et al. A missense mutation in FIC1 is associated with Greenland familial cholestasis. Hepatology. 2000; 32(6):1337-1341. [PubMed: 11093741]

58. Paulusma CC, Elferink RP, Jansen PL. Progressive familial intrahepatic cholestasis type 1. Semin. Liver Dis. 2010; 30(2):117-124. [PubMed: 20422494]

59. Folmer DE, van der Mark VA, Ho-Mok KS, Oude Elferink RP, Paulusma CC. Differential effects of progressive familial intrahepatic cholestasis type 1 and benign recurrent intrahepatic cholestasis type 1 mutations on canalicular localization of ATP8B1. Hepatology. 2009; 50(5):1597-1605. [PubMed: 19731236]

60. Bull LN, Carlton VE, Stricker NL, et al. Genetic and morphological findings in progressive familial intrahepatic cholestasis (Byler disease [PFIC-1] and Byler syndrome): evidence for heterogeneity. Hepatology. 1997; 26(1):155-164. [PubMed: 9214465]

61. Mullenbach R, Bennett A, Tetlow N, et al. ATP8B1 mutations in British cases with intrahepatic cholestasis of pregnancy. Gut. 2005; 54(6):829-834. [PubMed: 15888793]

62. Painter JN, Savander M, Ropponen A, et al. Sequence variation in the ATP8B1 gene and intrahepatic cholestasis of pregnancy. Eur. J. Hum. Genet. 2005; 13(4):435-439. [PubMed: 15657619]

63. Paulusma CC, de Waart DR, Kunne C, Mok KS, Elferink RP. Activity of the bile salt export pump (ABCB11) is critically dependent on canalicular membrane cholesterol content. J. Biol. Chem. 2009; 284(15):9947-9954. [PubMed: 19228692]

64. Stapelbroek JM, vanErpecum KJ, Klomp LW, Houwen RH. Liver disease associated with canalicular transport defects: current and future therapies. J. Hepatol. 2010; 52(2):258-271. [PubMed: 20034695]

65. Repa JJ, Mangelsdorf DJ. The role of orphan nuclear receptors in the regulation of cholesterol homeostasis. Annu. Rev. Cell Dev. Biol. 2000; 16:459-481. [PubMed: 11031244]

66. Botham KM, Bravo E. The role of lipoprotein cholesterol in biliary steroid secretion. Studies with in vivo experimental models. Prog. Lipid Res. 1995; 34(1):71-97. [PubMed: 7644554]

67. Schwartz CC, Halloran LG, Vlahcevic ZR, Gregory DH, Swell L. Preferential utilization of free cholesterol from high-density lipoproteins for biliary cholesterol secretion in man. Science. 1978; 200(4337):62-64. [PubMed: 204996]

68. Hillebrant CG, Nyberg B, Einarsson K, Eriksson M. The effect of plasma low density lipoprotein apheresis on the hepatic secretion of biliary lipids in humans. Gut. 1997; 41(5):700-704. [PubMed: 9414982] 
69. Salen G, Shefer S, Nguyen L, Ness GC, Tint GS, Shore V. Sitosterolemia. J. Lipid Res. 1992; 33(7):945-955. [PubMed: 1431587]

70. Heinemann T, Axtmann G, von Bergmann K. Comparison of intestinal absorption of cholesterol with different plant sterols in man. Eur. J. Clin. Invest. 1993; 23(12):827-831. [PubMed: 8143759]

71. Bosner MS, Lange LG, Stenson WF, Ostlund RE Jr. Percent cholesterol absorption in normal women and men quantified with dual stable isotopic tracers and negative ion mass spectrometry. J. Lipid Res. 1999; 40(2):302-308. [PubMed: 9925660]

72. Patel SB, Salen G, Hidaka H, et al. Mapping a gene involved in regulating dietary cholesterol absorption. The sitosterolemia locus is found at chromosome 2p21. J. Clin. Invest. 1998; 102(5): 1041-1044. [PubMed: 9727073]

73. Berge KE, Tian H, Graf GA, et al. Accumulation of dietary cholesterol in sitosterolemia caused by mutations in adjacent ABC transporters. Science. 2000; 290(5497):1771-1775. [PubMed: 11099417]

74. Lee MH, Lu K, Hazard S, et al. Identification of a gene $A B C G 5$, important in the regulation of dietary cholesterol absorption. Nat. Genet. 2001; 27(1):79-83. [PubMed: 11138003]

75. Lu K, Lee MH, Hazard S, et al. Two genes that map to the STSL locus cause sitosterolemia: genomic structure and spectrum of mutations involving sterolin-1 and sterolin-2, encoded by $A B C G 5$ and $A B C G 8$, respectively. Am. J. Hum. Genet. 2001; 69(2):278-290. [PubMed: 11452359]

76. Graf GA, Yu L, Li WP, et al. ABCG5 and ABCG8 are obligate heterodimers for protein trafficking and biliary cholesterol excretion. J. Biol. Chem. 2003; 278(48):48275-48282. [PubMed: 14504269]

77. Klett EL, Lee MH, Adams DB, Chavin KD, Patel SB. Localization of ABCG5 and ABCG8 proteins in human liver, gall bladder and intestine. BMC Gastroenterol. 2004; 4:21. [PubMed: 15383151]

78. Kosters A, Kunne C, Looije N, Patel SB, Oude Elferink RP, Groen AK. The mechanism of ABCG5/ABCG8 in biliary cholesterol secretion in mice. J. Lipid Res. 2006; 47(9):1959-1966. [PubMed: 16741293]

79. Small DM. Role of ABC transporters in secretion of cholesterol from liver into bile. Proc. Natl Acad. Sci. USA. 2003; 100(1):4-6. [PubMed: 12509503]

80. Bhattacharyya AK, Connor WE. Beta-sitosterolemia and xanthomatosis. A newly described lipid storage disease in two sisters. J. Clin. Invest. 1974; 53(4):1033-1043. [PubMed: 4360855]

81. Lutjohann D, Bjorkhem I, Beil UF, von Bergmann K. Sterol absorption and sterol balance in phytosterolemia evaluated by deuterium-labeled sterols: effect of sitostanol treatment. J. Lipid Res. 1995; 36(8):1763-1773. [PubMed: 7595097]

82. Miettinen TA, Klett EL, Gylling H, Isoniemi H, Patel SB. Liver transplantation in a patient with sitosterolemia and cirrhosis. Gastroenterology. 2006; 130(2):542-547. [PubMed: 16472606]

83. Tsubakio-Yamamoto K, Nishida M, Nakagawa-Toyama Y, Masuda D, Ohama T, Yamashita S. Current therapy for patients with sitosterolemia-effect of ezetimibe on plant sterol metabolism. J. Atheroscler. Thromb. 2010; 17(9):891-900. [PubMed: 20543520]

84. Salen G, Starc T, Sisk CM, Patel SB. Intestinal cholesterol absorption inhibitor ezetimibe added to cholestyramine for sitosterolemia and xanthomatosis. Gastroenterology. 2006; 130(6):1853-1857. [PubMed: 16697747]

85. Lutjohann D, von Bergmann K, Sirah W, et al. Long-term efficacy and safety of ezetimibe $10 \mathrm{mg}$ in patients with homozygous sitosterolemia: a 2-year, open-label extension study. Int. J. Clin. Pract. 2008; 62(10):1499-1510. [PubMed: 18822021]

86. Altmann SW, Davis HR Jr, Zhu LJ, et al. Niemann-Pick C1 Like 1 protein is critical for intestinal cholesterol absorption. Science. 2004; 303(5661):1201-1204. [PubMed: 14976318]

87. Davis HR Jr, Zhu LJ, Hoos LM, et al. Niemann-Pick C1 Like 1 (NPC1L1) is the intestinal phytosterol and cholesterol transporter and a key modulator of whole-body cholesterol homeostasis. J. Biol. Chem. 2004; 279(32):33586-33592. [PubMed: 15173162]

88. Garcia-Calvo M, Lisnock J, Bull HG, et al. The target of ezetimibe is Niemann-Pick C1-Like 1 (NPC1L1). Proc. Natl Acad. Sci. USA. 2005; 102(23):8132-8137. [PubMed: 15928087] 
89. Davies JP, Scott C, Oishi K, Liapis A, Ioannou YA. Inactivation of NPC1L1 causes multiple lipid transport defects and protects against diet-induced hypercholesterolemia. J. Biol. Chem. 2005; 280(13):12710-12720. [PubMed: 15671032]

90. Temel RE, Tang W, Ma Y, et al. Hepatic Niemann-Pick C1-like 1 regulates biliary cholesterol concentration and is a target of ezetimibe. J. Clin. Invest. 2007; 117(7):1968-1978. [PubMed: 17571164]

91. Kamisako T, Leier I, Cui Y, et al. Transport of monoglucuronosyl and bisglucuronosyl bilirubin by recombinant human and rat multidrug resistance protein 2. Hepatology. 1999; 30(2):485-490. [PubMed: 10421658]

92. Taniguchi K, Wada M, Kohno K, et al. A human canalicular multispecific organic anion transporter ( $c M O A T)$ gene is overexpressed in cisplatin-resistant human cancer cell lines with decreased drug accumulation. Cancer Res. 1996; 56(18):4124-4129. [PubMed: 8797578]

93. Toh S, Wada M, Uchiumi T, et al. Genomic structure of the canalicular multispecific organic anion-transporter gene (MRP2/cMOAT) and mutations in the ATP-binding-cassette region in Dubin-Johnson syndrome. Am. J. Hum. Genet. 1999; 64(3):739-746. [PubMed: 10053008]

94. Tsujii H, Konig J, Rost D, Stockel B, Leuschner U, Keppler D. Exon-intron organization of the human multidrug-resistance protein 2 (MRP2) gene mutated in Dubin-Johnson syndrome. Gastroenterology. 1999; 117(3):653-660. [PubMed: 10464142]

95. Jemnitz K, Heredi-Szabo K, Janossy J, Ioja E, Vereczkey L, Krajcsi P. ABCC2/Abcc2: a multispecific transporter with dominant excretory functions. Drug Metab. Rev. 2010; 42(3):402436. [PubMed: 20082599]

96. Schaub TP, Kartenbeck J, Konig J, et al. Expression of the MRP2 gene-encoded conjugate export pump in human kidney proximal tubules and in renal cell carcinoma. J. Am Soc. Nephrol. 1999; 10(6):1159-1169. [PubMed: 10361853]

97. Fromm MF, Kauffmann HM, Fritz P, et al. The effect of rifampin treatment on intestinal expression of human MRP transporters. Am. J. Pathol. 2000; 157(5):1575-1580. [PubMed: 11073816]

98. Nies AT, Konig J, Pfannschmidt M, Klar E, Hofmann WJ, Keppler D. Expression of the multidrug resistance proteins MRP2 and MRP3 in human hepatocellular carcinoma. Int. J. Cancer. 2001; 94(4):492-499. [PubMed: 11745434]

99. Sandusky GE, Mintze KS, Pratt SE, Dantzig AH. Expression of multidrug resistance-associated protein 2 (MRP2) in normal human tissues and carcinomas using tissue microarrays. Histopathology. 2002; 41(1):65-74. [PubMed: 12121239]

100. Dubin IN, Johnson FB. Chronic idiopathic jaundice with unidentified pigment in liver cells; a new clinicopathologic entity with a report of 12 cases. Medicine (Baltimore). 1954; 33(3):155197. [PubMed: 13193360]

101. Rastogi A, Krishnani N, Pandey R. Dubin-Johnson syndrome - a clinicopathologic study of twenty cases. Indian J. Pathol. Microbiol. 2006; 49(4):500-504. [PubMed: 17183837]

102. Donner MG, Keppler D. Up-regulation of basolateral multidrug resistance protein 3 (Mrp3) in cholestatic rat liver. Hepatology. 2001; 34(2):351-359. [PubMed: 11481620]

103. Nisa AU, Ahmad Z. Dubin-Johnson syndrome. J. Coll. Physicians Surg. Pak. 2008; 18(3):188189. [PubMed: 18460254]

104. Nies AT, Keppler D. The apical conjugate efflux pump ABCC2 (MRP2). Pflugers Arch. 2007; 453(5):643-659. [PubMed: 16847695]

105. Welch EM, Barton ER, Zhuo J, et al. PTC124 targets genetic disorders caused by nonsense mutations. Nature. 2007; 447(7140):87-91. [PubMed: 17450125]

106. van der Velden LM, Stapelbroek JM, Krieger E, et al. Folding defects in P-type ATP 8B1 associated with hereditary cholestasis are ameliorated by 4-phenylbutyrate. Hepatology. 2010; 51(1):286-296. [PubMed: 19918981]

107. Hayashi H, Sugiyama Y. 4-phenylbutyrate enhances the cell surface expression and the transport capacity of wild-type and mutated bile salt export pumps. Hepatology. 2007; 45(6):1506-1516. [PubMed: 17538928] 
108. Collin J, Lako M. Concise review: putting a finger on stem cell biology: zinc finger nucleasedriven targeted genetic editing in human pluripotent stem cells. Stem Cells. 2011; 29(7):10211033. [PubMed: 21544904]

109. Miller JC, Tan S, Qiao G, et al. A TALE nuclease architecture for efficient genome editing. Nat. Biotechnol. 2011; 29(2):143-148. [PubMed: 21179091]

110. Ellis BL, Hirsch ML, Porter SN, Samulski RJ, Porteus MH. Zinc-finger nuclease-mediated gene correction using single AAV vector transduction and enhancement by Food and Drug Administration-approved drugs. Gene Ther. 2012 (Epub ahead of print). 


\section{Executive summary}

\section{Canalicular transport of bile salts}

- Bile salt secretion is mediated by $\mathrm{ABCB} 11$. Bile salt transport across the canalicular membrane is the major driving force for bile flow.

- $\quad$ Progressive familial intrahepatic cholestasis (PFIC) type 2 is caused by mutations in $A B C B 11$ that lead to very low levels of bile salts in bile, but high levels in serum.

\section{Canalicular transport of phosphatidylcholine}

- Phosphatidylcholine (PC) secretion is mediated by ABCB4. The main function of $\mathrm{PC}$ in bile is to reduce the detergent activity of bile salts by forming mixed micelles of PC and bile salts.

- The liver disease PFIC type 3 is caused by mutations in $A B C B 4$ and is characterized by low levels of PC in bile and high levels of $\gamma$ glutamyltransferase in serum.

\section{Canalicular transport of cholesterol \& plant sterols}

- $\quad$ ABCG5 and ABCG8 function as obligate heterodimers to efflux cholesterol and plant sterols from hepatocytes into bile as well as from enterocytes into the intestinal lumen.

- Mutations in $A B C G 5$ or $A B C G 8$ cause sitosterolemia, which is characterized by elevated serum levels of plant sterols.

\section{Canalicular transport of organic anions}

- $\mathrm{ABCC} 2$ transports bilirubin glucuronides and many compounds conjugated with glutathione, glucuronate and sulfate.

- Dubin-Johnson syndrome is caused by $A B C C 2$ mutations that lead to hyperbilirubinemia and a darkly pigmented liver.

\section{ATP8B1 maintains the canalicular membrane in the liquid-ordered state}

- ATP8B1 translocates phosphatidylserine from the outer to the inner leaflet of the canalicular membrane.

- $\quad$ PFIC type 1 is caused by mutations in ATP8B1. PFIC type 1 patients have low levels of bile salts in bile, and they exhibit extrahepatic symptoms because ATP8B1 expression is not restricted to the liver. 


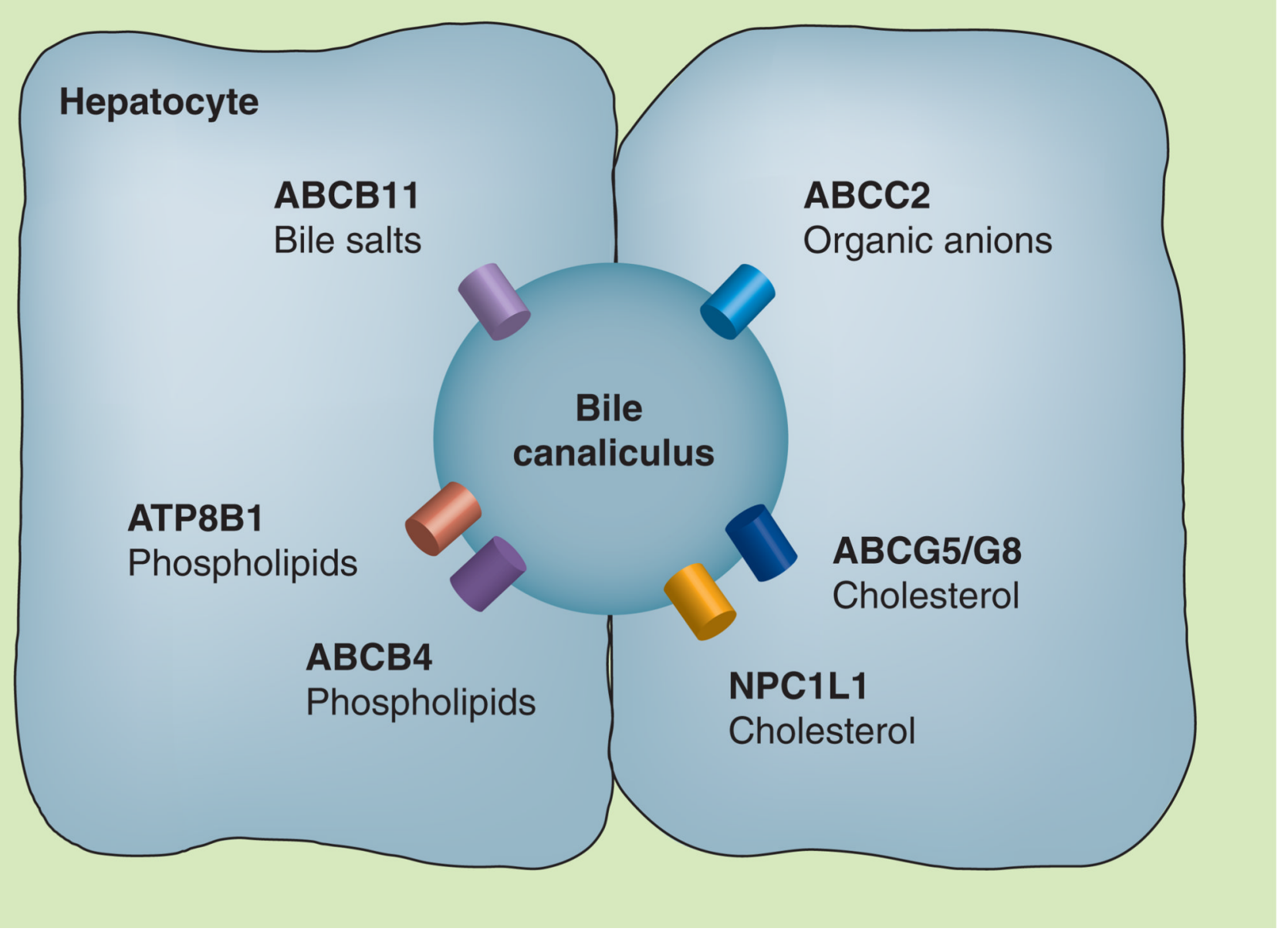

Figure 1. Canalicular proteins involved in bile formation

All of the ABC proteins transport organic solutes into the canalicular lumen. The ATP8B1 protein does not transport organic solutes into the bile but translocates phospholipids from the outer to the inner leaflet of the canalicular membrane of hepatocytes. The NPCIL1 protein transports cholesterol from the lumen back to the liver.

ABC: ATP-binding cassette. 


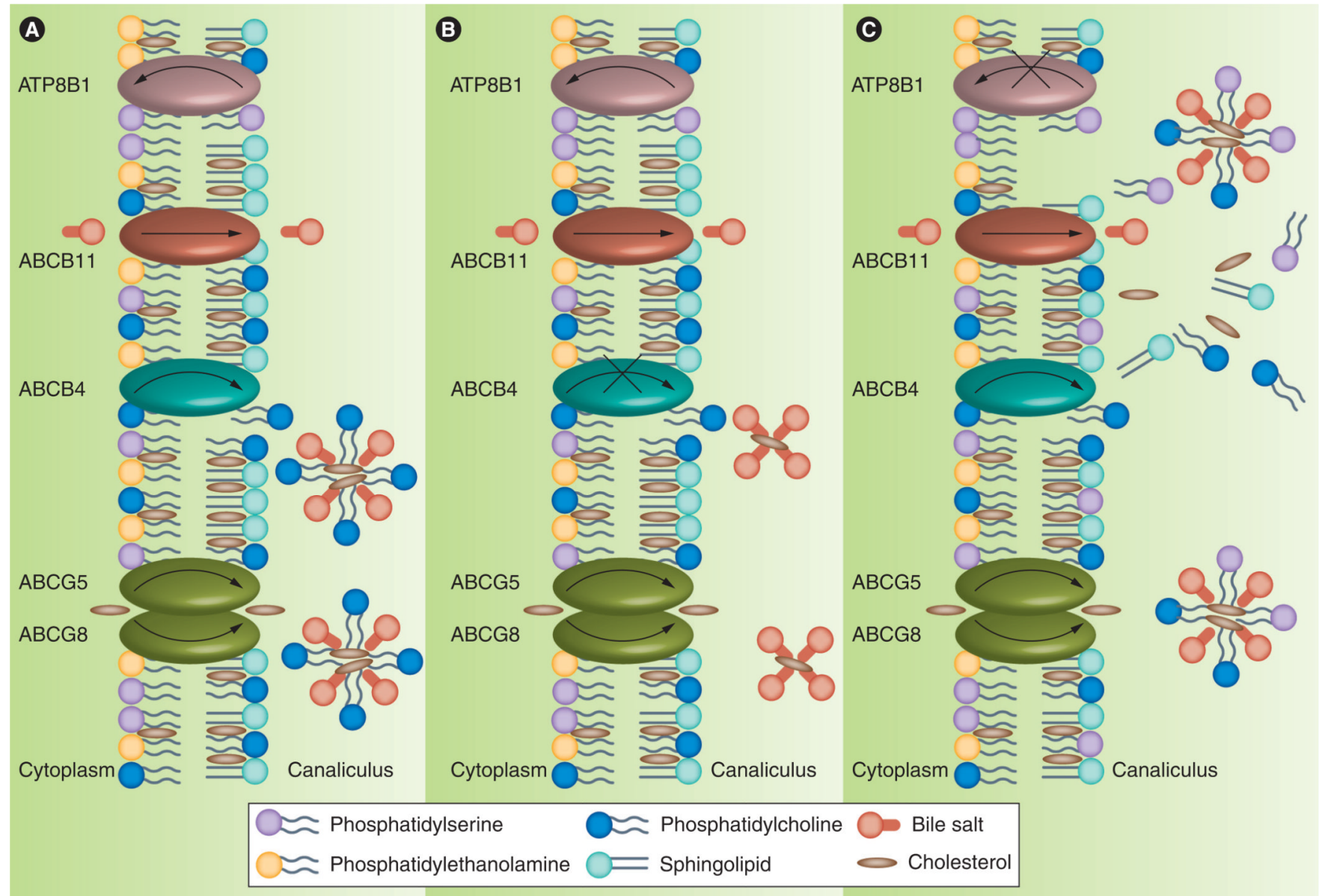

Figure 2. Biliary lipid secretion at the canalicular membrane

(A) In normal individuals, ABCB11, ABCB4 and ABCG5-ABCG8 secrete bile salts, phosphatidylcholine (PC), and cholesterol, respectively, into bile. PC and cholesterol form mixed micelles with bile salts to reduce the detergent activity of bile salts, protecting the canalicular membrane from attack by bile salts. The asymmetry of phospholipids in the membrane bilayer, where phosphatidylserine (PS), phosphatidylethanolamine and PC are in the inner leaflet, and sphingolipids, cholesterol and PC are in the outer leaflet, makes the canalicular membrane resistant to bile salts. Extraction of PC from the outer leaflet by bile salts allows PS to flop to the outer leaflet. However, the ATP8B1 protein flips PS back to the inner leaflet and maintains the membrane bilayer in a liquid-ordered state. (B) In progressive familial intrahepatic cholestasis type 3 patients, $A B C B 4$ mutations impair biliary secretion of PC. Bile salts are present in the bile as monomeric bile salts or simple bile salt micelles. The canalicular membrane is more vulnerable to solubilization by bile salts because simple bile salt micelles, which lack PC, have stronger detergent activity than mixed bile salt micelles. (C) In progressive familial intrahepatic cholestasis type 1 patients, $A T P 8 B 1$ mutations lead to accumulation of PS in the outer leaflet. The membrane is in the liquid-disordered state and is susceptible to damage by bile salts. Bile salts also extract PS and cholesterol from the canalicular membrane. Changes in the lipid composition of the membrane, especially a reduction in cholesterol content, impair bile flow and lead to cholestasis. 
Table 1

Characteristics of the three types of progressive familial intrahepatic cholestasis disorders.

\begin{tabular}{|c|c|c|c|}
\hline & PFIC1 & PFIC2 & PFIC3 \\
\hline Functional defect & PS flippase activity & Bile salt secretion & PC secretion \\
\hline \multicolumn{4}{|l|}{ Genes \& proteins } \\
\hline Gene name & ATP8B1 & $A B C B 11$ & $A B C B 4$ \\
\hline Gene location & $18 \mathrm{q} 21$ & $2 \mathrm{q} 24$ & $7 \mathrm{q} 21$ \\
\hline Protein name & ATP8B1 & $\mathrm{ABCB} 11$ & АВCB4 \\
\hline Alternative protein name & FIC1 & BSEP, SPGP & MDR3 \\
\hline \multicolumn{4}{|l|}{ Clinical symptoms $^{\dagger}$} \\
\hline Onset of jaundice & Birth to 9 months & Birth to 6 months & 1 month to 20 years \\
\hline Progression to cirrhosis & $2-7$ years & 6 months to 10 years & 5 months to 20 years \\
\hline Pruritus & Severe & Severe & Moderate \\
\hline Cholelithiasis & No & Yes & Yes \\
\hline Extrahepatic symptoms & Diarrhea, hearing loss, pancreatitis, pneumonia & None & None \\
\hline \multicolumn{4}{|l|}{ Biochemical tests: serum ${ }^{\dagger}$} \\
\hline ALT & Elevated & Elevated (fivefold) & Elevated (fivefold) \\
\hline$\gamma \mathrm{GT}$ & Normal/low & Normal/low & High \\
\hline Bile salts & High & High & High \\
\hline Cholesterol & Sometimes elevated & Often elevated & Normal \\
\hline \multicolumn{4}{|l|}{ Biochemical tests: bile ${ }^{\dagger}$} \\
\hline Bile salts & Low & Very low & Normal \\
\hline Phospholipids & Normal & Normal & Low \\
\hline \multicolumn{4}{|l|}{ Histology ${ }^{\dagger}$} \\
\hline Bile duct proliferation & No & Yes & Yes \\
\hline Portal fibrosis (at presentation) & No & Yes (not always) & Yes \\
\hline Cirrhosis (before first year) & No & Yes & No \\
\hline Giant cell hepatitis & No & Yes & No \\
\hline \multicolumn{4}{|l|}{ Electron microscopy ${ }^{\dagger}$} \\
\hline Bile characteristics & Coarse and granular & Amorphous & Cholesterol crystals \\
\hline
\end{tabular}

${ }^{\dagger}$ Data taken with permission from [25].

ALT: Alanine aminotransferase; $\gamma$ GT: $\gamma$-glutamyltransferase; PC: Phosphatidylcholine; PFIC: Progressive familial intrahepatic cholestasis; PS: Phosphatidylserine. 